\title{
Drug-Drug Interaction Studies of Levocetirizine with
}

\section{Atenolol}

Shafaque Mehboob ${ }^{1}$, Muhammad Azhar Mughal ${ }^{2}$, Khalid Aftab ${ }^{3}$, Moona Mehboob Khan ${ }^{4}$, Najma Sultana ${ }^{5}$ and Syed Arayne ${ }^{5}$

1. Institute of Pharmaceutical Sciences, Jinnah Sindh Medical University, Karachi 75510, Pakistan

2. Department of Pharmacology \& Therapeutics, Jinnah Sindh Medical University, Karachi 75510, Pakistan

3. Department of Pharmacology \& Therapeutics, Islam Medical \& Dental College, Sialkot 51311, Pakistan

4. Department of Pharmaceutical Chemistry, Dow University of Health Sciences, Karachi 74200, Pakistan

5. Department of Pharmaceutical Chemistry, Faculty of Pharmacy, University of Karachi, Karachi 75270, Pakistan

\begin{abstract}
The objective of the study was to evaluate the drug-drug interaction studies of levoceterizine with atenolol. Calibration curve studies of working standard solutions of levocetirizine and atenolol (0.01 0.1 mmol) were scanned. Maxima appeared at $231 \mathrm{~nm}$ for levocetirizine and $224 \mathrm{~nm}$ for atenolol. The calibration curve obeyed Beer Lambert's Law. Lone availabilities of both the drugs were studied in $\mathrm{pH} 1, \mathrm{pH} 4, \mathrm{pH} 7.4$ and $\mathrm{pH} 9$ at $37{ }^{\circ} \mathrm{C}$ on B.P. (British Pharmacopoeia) dissolution apparatus. To study the drug-drug interaction of levocetirizine ( $5 \mathrm{mg}$ tablet) and atenolol (100 $\mathrm{mg}$ tablet), both the drugs were introduced to the dissolution apparatus in simulated gastric juice $(\mathrm{pH} 1), \mathrm{pH} 4, \mathrm{pH} 7.4$ and $\mathrm{pH} 9$ at $37{ }^{\circ} \mathrm{C}$ at zero time and measured the absorbance maxima of both the drugs at the corresponding wavelength. Graphs were plotted for availability percentage (\%) of drug versus time at each set of experiment. The availability percentage (\%) of levocetirizine in the buffers of $\mathrm{pH}$ simulated to gastric $\mathrm{pH} 4, \mathrm{pH} 7.4$ and $\mathrm{pH} 9$ in the presence of atenolol was $436.78 \%, 376.90 \%, 436.78 \%$ and $436.78 \%$, respectively, but the availability of atenolol was increased up to $214.80 \%, 212.96 \%, 214.93 \%$ and $231.51 \%$ in simulated to gastric $\mathrm{pH}$ and in the buffers of $\mathrm{pH} 4, \mathrm{pH} 7.4$ and $\mathrm{pH}$, respectively. On the basis of these studies, it is concluded that levocetirizine forms a charge-complex with atenolol; therefore, co-administration of these drugs should be avoided.
\end{abstract}

Key words: Levocetirizine, atenolol, drug-drug interactions, absorbance maxima.

\section{Introduction}

Levocetirizine is a third generation non-sedative anti-histamine, developed from the second generation anti-histamine cetirizine and works by blocking histamine receptors. It does not prevent the release of histamine from mast cells, but prevents its binding from its receptors. This, in turn, prevents the release of other allergic chemicals and increased blood supply to the area, and provides relief from the typical symptoms of hay fever and used to manage intermittent and persistent allergic rhinitis [1].

The qualitative assays of levocetirizine have been performed in different subjects to determine the

Corresponding author: Khalid Aftab, Ph.D., professor, research fields: pharmacology and phyto-pharmacology. anti-allergic activity of the drug [2-7]. UV (ultraviolet) detection was performed for the quantification of levocetirizine in the tablets and for enantiomeric purity testing of the drug by a validated, selective, precise and accurate method [8].

For the treatment of patients with seasonal and perennial allergic rhinitis with or without concurrent asthma, levocetirizine was reported $5 \mathrm{mg}$ once daily for 32 days. Alleviation and improvement of the symptoms, such as rhinorrhea, sneezing, conjunctivitis, and asthmatic symptoms, were observed in over $80 \%$ of the patients at the end of the experiment [9-10]. As compared to cetirizine, levocetirizine of $5 \mathrm{mg}$ dosage is pharmacokinetically equal to $10 \mathrm{mg}$ cetirizine [11].

Levocetirizine and dextrocetirizine may have consequences for drug interactions at the renal level 
[12]. Levocetirizine is a weak $\operatorname{PgP}$ (P-glycoprotein) substrate; therefore, it should be taken with cautions with the drugs which are either PgP substrate, such as ketoconazole, cyclosporine or verapamil, or PgP inducers like rifampicin or inhibitor, such as erythromycin, azithromycin or itraconazole [13, 14].

Atenolol is a $\beta$-adrenolytic, cardio-selective drug efficient in cases of arterial hypertension and cardiac arrhythmias. Its adverse effects include fatigue, sleep disturbance and depressions. Many sensitive methods are reported for the quantitative determination of atenolol in different dosages, as well as samples including spectroflurometric method, RP-HPLC (reverse phase-high performance liquid chromatography) method, APCI (atmospheric pressure ionization interface) method and RP-HPLC method [15-18].

Many drug interactions of atenolol have been reported. Enalapril and atenolol give less hypotensive effects when given together, with attenuation of the potential additive response by $30 \sim 50 \%$.

Atenolol acted synergistically only at a low hydralazine dose. Moreover, it interfered with the vasodilator response of hydralazine in the heart, skeletal muscles and the arteriovenous anastomosis and abolished the negative effect of hydralazine on this parameter. It also interacts with metal [19].

The object of present work is to evaluate the possible drug-drug interactions of levoceterizine with atenolol if co-administered.

\section{Methodology}

To study drug interactions, reported methods were followed [20]. Reference standard of levocetirizine was gifted by Hilton Pharma (Pvt.), Karachi, whereas, atenolol was given by Zafa Pharmaceutical Laboratories (Pvt.) Ltd., Karachi. Each product was labeled properly and expiry dates checked and they were not earlier than two years at the time of study. All the reagents used were of analytical grade and all the glassware were used of Pyrex brand.

\subsection{Equipments}

Using the following calibrated equipments, analytical measurements were carried out. Electrical balance (Mettler Toledo AB54), pH meter (Mettler Toledo MP220), UV visible spectrophotometer (Model 1606, Shimadzu, Japan) with $10 \mathrm{~mm}$ path length connected to a P-IV computer loaded with Shimadzu UVPC Version 3.9 software was used in these studies, $1 \mathrm{~cm}$ rectangular quartz cells, ground glass distillation assembly, water distillation unit (GEL type 2001/2, No. 10793600G), melting point apparatus (Gallenkamp) and deionizer (Stedec CSW-300) were used. The dissolution equipment was manufactured to the B.P. 2007 standard.

\subsection{Preparation of Solutions}

Levocetirizine $0.04254 \mathrm{gm}$ and atenolol $0.0266 \mathrm{gm}$ were weighed accurately and each drug dissolved in one liter of buffers of $\mathrm{pH} 1 \sim 9$ to get primary solution of $1 \mathrm{mmol}$, from that the stock solution of $0.1 \mathrm{mmol}$ was prepared by diluting $25 \mathrm{~mL}$ of primary solution into $250 \mathrm{~mL}$ volumetric flask containing corresponding buffers. Different dilutions ranging from 0.01 to $0.1 \mathrm{mmol}$ were prepared by diluting the stock solutions $(0.1 \mathrm{mmol})$ with different buffer solutions of $\mathrm{pH}$ 9. For this purpose, 5, 10, 15, 20, 25, $30,35,40$ and $45 \mathrm{~mL}$ of stock solutions were separately pipette out in nine different $50 \mathrm{~mL}$ volumetric flasks and diluted with individual buffer solutions up to the mark to prepare the working solutions of 0.01 0.09 mmol. These solutions were used for calibration curve studies.

\subsection{Calibration Curve Studies}

Working standard solutions of both the drugs of $0.01 \sim 0.1 \mathrm{mmol}$ were prepared for this purpose. The absorbance maxima were scanned in the region of 200 700 nm against the reagent blank. Maxima appeared at $231 \mathrm{~nm}$ for levocetirizine and $224 \mathrm{~nm}$ for atenolol. The calibration curve was plotted for absorbance against concentration and straight lines 
were obtained which obeyed Beer Lambert's Law. Epsilon value was also calculated from these observations.

\subsection{In Vitro Availability Studies}

The in vitro availability of levocetirizine was studied in simulated gastric juice ( $\mathrm{pH} 1), \mathrm{pH} 4, \mathrm{pH} 7.4$ and in $\mathrm{pH} 9$ at $37^{\circ} \mathrm{C}$ on B.P. dissolution apparatus. 5 $\mathrm{mg}$ of levocetirizine was introduced in $1 \mathrm{~L}$ dissolution medium. Aliquots of $5 \mathrm{~mL}$ were withdrawn intermittently at $15 \mathrm{~min}$ time intervals for $120 \mathrm{~min}$ and assayed for the drug contents. The volume of the dissolution fluid was maintained by adding an equivalent amount of dissolution fluid withdrawn in the same bath at the same temperature. The sample was scanned in the region 200 700 nm against blank. The same procedure was adopted to calculate the availability of $100 \mathrm{mg}$ of atenolol tablet.

\subsection{Drug-Drug Interaction Studies of Levocetirizine and Atenolol}

To study the drug-drug interaction of levocetirizine (5 mg tablet) and atenolol (100 mg tablet), both the drugs were introduced to the dissolution medium at zero time. Same procedure was adopted to measure the absorbance maxima of both the drugs at the corresponding wavelength. Figs. 1 and 2 (Tables 1 and 2) were also plotted for availability percentage (\%) of drug versus time at each set of experiment.

\section{Results}

Levocetirizine and atenolol interfere at each other's wavelength. The lone availability of both the drugs in all the $\mathrm{pH}$ calculated not more than $115 \%$. After the interaction, availabilities of levocetirizine, as well as atenolol, increased in the presence of each other in simulated gastric juice and the rest of the buffers. At

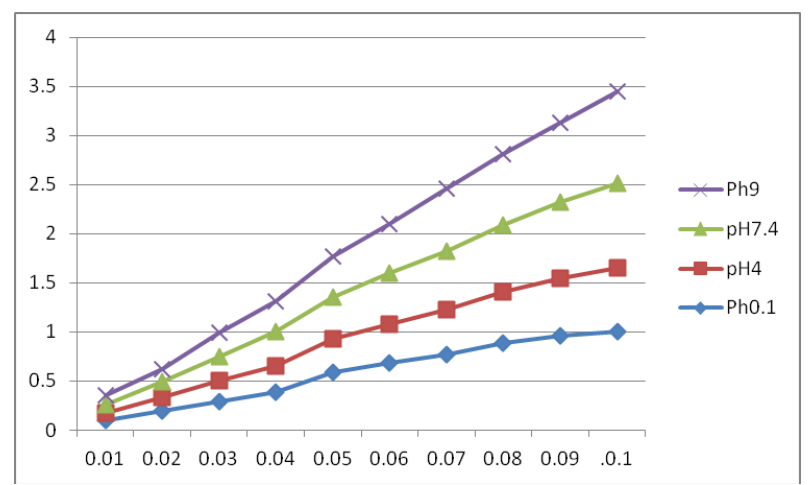

Fig. 1 Concentration (mmol) and corresponding absorbance graph of levocetirizine in different $\mathrm{pH}$.

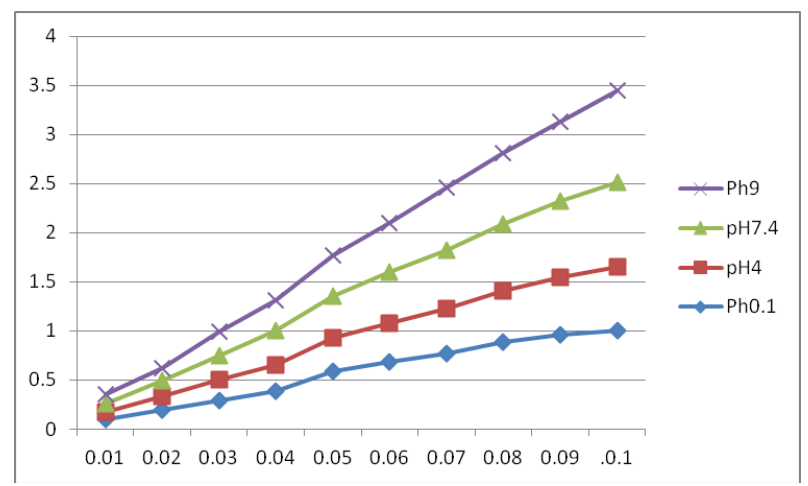

Fig. 2 Concentration (mmol) and corresponding absorbance graph of Atenolol in different $\mathrm{pH}$.

Table 1 Concentration and corresponding absorbance of levocetirizine in different $\mathrm{pH}$.

\begin{tabular}{lllll}
\hline Concentration (mmol) & $\mathrm{pH} 1$ & $\mathrm{pH} 4$ & $\mathrm{pH} 7.4$ & $\mathrm{pH} \mathrm{9}$ \\
\hline 0.01 & 0.1675 & 0.1431 & 0.1278 & 0.1414 \\
0.02 & 0.327 & 0.2711 & 0.25 & 0.2843 \\
0.03 & 0.4965 & 0.4159 & 0.3739 & 0.4274 \\
0.04 & 0.6499 & 0.5604 & 0.4697 & 0.5695 \\
0.05 & 0.8054 & 0.7032 & 0.6152 & 0.7112 \\
0.06 & 0.969 & 0.8503 & 0.739 & 0.8602 \\
0.07 & 1.1246 & 0.9906 & 0.8638 & 0.986 \\
0.08 & 1.439 & 1.1398 & 0.9844 & 1.1398 \\
0.09 & 1.4498 & 1.2775 & 1.1123 & 1.2853 \\
0.10 & 1.6012 & 1.4381 & 1.235 & 1.4541 \\
\hline
\end{tabular}


Table 2 Concentration and corresponding absorbance of atenolol in different $\mathrm{pH}$.

\begin{tabular}{lllll}
\hline Concentration (mmol) & $\mathrm{pH} \mathrm{1}$ & $\mathrm{pH} \mathrm{4}$ & $\mathrm{pH} \mathrm{7.4}$ & $\mathrm{pH} \mathrm{9}$ \\
\hline 0.01 & 0.1034 & 0.0753 & 0.0856 & 0.0936 \\
0.02 & 0.1914 & 0.1372 & 0.1667 & 0.1236 \\
0.03 & 0.2877 & 0.2125 & 0.2528 & 0.2421 \\
0.04 & 0.3843 & 0.2682 & 0.3457 & 0.3131 \\
0.05 & 0.5907 & 0.3342 & 0.4322 & 0.4167 \\
0.06 & 0.6842 & 0.3937 & 0.5183 & 0.5038 \\
0.07 & 0.7704 & 0.4572 & 0.5981 & 0.6361 \\
0.08 & 0.8817 & 0.5269 & 0.6803 & 0.7241 \\
0.09 & 0.9626 & 0.5818 & 0.7727 & 0.8160 \\
0.1 & 1.0028 & 0.6473 & 0.8600 & 0.9357 \\
\hline
\end{tabular}

Table 3 Availability (\%) of levocetirizine and atenolol in simulated gastric juice after interaction.

\begin{tabular}{lllll}
\hline Serial No. & $\begin{array}{l}\text { Levocetirizine } \\
(231 \mathrm{~nm})\end{array}$ & $\begin{array}{l}\text { Atenolol } \\
(224 \mathrm{~nm})\end{array}$ & $\begin{array}{l}\text { Percentage of available } \\
\text { levocetirizine }(\%)\end{array}$ & $\begin{array}{l}\text { Percentage of available } \\
\text { atenolol }(\%)\end{array}$ \\
\hline 0 & 0 & 0 & 0 & 0 \\
15 & 0.0193 & 0.0221 & 17.27 & 2.09 \\
30 & 1.4116 & 1.4807 & 376.9 & 51.34 \\
45 & 1.4321 & 1.8826 & 397.15 & 208.27 \\
60 & 1.4404 & 1.9055 & 401.38 & 210.37 \\
75 & 1.4448 & 1.9143 & 406.92 & 211.12 \\
90 & 1.4520 & 1.9186 & 413.32 & 211.44 \\
105 & 1.46778 & 1.9333 & 418.04 & 213.57 \\
120 & 1.4753 & 1.9497 & 436.78 & 214.80 \\
\hline
\end{tabular}

Table 4 Availability (\%) of levocetirizine and atenolol in pH 4 after interaction.

\begin{tabular}{lllll}
\hline Serial No. & $\begin{array}{l}\text { Levocetirizine } \\
(231 \mathrm{~nm})\end{array}$ & $\begin{array}{l}\text { Atenolol } \\
(224 \mathrm{~nm})\end{array}$ & $\begin{array}{l}\text { Percentage of available } \\
\text { levocetirizine }(\%)\end{array}$ & $\begin{array}{l}\text { Percentage of available } \\
\text { atenolol }(\%)\end{array}$ \\
\hline 0 & 0.00 & 0.00 & 0.00 & 0.00 \\
15 & 1.2935 & 1.7363 & 305.28 & 193.18 \\
30 & 1.3365 & 1.8011 & 305.54 & 201.07 \\
45 & 1.3699 & 1.8034 & 308.06 & 203.39 \\
60 & 1.3726 & 1.8348 & 308.47 & 205.28 \\
75 & 1.3743 & 1.8422 & 315.12 & 206.08 \\
90 & 1.3799 & 1.8513 & 328.56 & 206.60 \\
105 & 1.3844 & 1.8523 & 352.46 & 208.08 \\
120 & 1.4089 & 1.8647 & 376.90 & 212.96 \\
\hline
\end{tabular}

the start of experiment in simulated gastric juice, $17.27 \%$ of the drug was available which exceeded to $436.78 \%$ till the end of the experiment. Similarly, in the buffers of $\mathrm{pH} \mathrm{4,} \mathrm{pH} 7.4$ and $\mathrm{pH}$ 9, an increased availability of levocetirizine was observed, i.e., $376.90 \%, 436.78 \%$ and $436.78 \%$, respectively. The availability of atenolol was increased up to $214.80 \%$, $212.96 \%, 214.93 \%$ and $231.51 \%$ (Fig. 3 and Tables 3-6) in simulated to gastric $\mathrm{pH}$ and in the buffers of $\mathrm{pH} 4, \mathrm{pH} 7.4$ and $\mathrm{pH}$ 9, respectively.

\section{Discussion}

This procedure was designed to simultaneously measure the quantities of two drugs present in the same solution without separating them. This was accomplished by developing the mathematical relationship between levocetirizine and interacting drug because both the drugs have interfered at each other's wavelength which gave the concentration of two drugs simultaneously, when maxima measured at 
Table 5 Availability (\%) of levocetirizine and atenolol in $\mathrm{pH} 7.4$ after interaction.

\begin{tabular}{lllll}
\hline Serial No. & $\begin{array}{l}\text { Levocetirizine } \\
(231 \mathrm{~nm})\end{array}$ & $\begin{array}{l}\text { Atenolol } \\
(224 \mathrm{~nm})\end{array}$ & $\begin{array}{l}\text { Percentage of available } \\
\text { levocetirizine }(\%)\end{array}$ & $\begin{array}{l}\text { Percentage of available } \\
\text { atenolol }(\%)\end{array}$ \\
\hline 0 & 0.00 & 0.00 & 0.00 & 0.00 \\
15 & 0.0193 & 0.0221 & 17.27 & 2.09 \\
30 & 1.4116 & 1.4807 & 376.90 & 51.34 \\
45 & 1.4321 & 1.9055 & 397.15 & 210.37 \\
60 & 1.4404 & 1.9143 & 398.27 & 208.27 \\
75 & 1.4448 & 1.9186 & 406.92 & 211.12 \\
90 & 1.4520 & 1.9055 & 413.32 & 211.44 \\
105 & 1.4678 & 1.9333 & 418.04 & 213.57 \\
120 & 1.4953 & 1.9497 & 436.78 & 214.93 \\
\hline
\end{tabular}

Table 6 Availability (\%) of levocetirizine and atenolol in $\mathrm{pH} 9$ after interaction.

\begin{tabular}{lllll}
\hline Serial No. & $\begin{array}{l}\text { Levocetirizine } \\
(231 \mathrm{~nm})\end{array}$ & $\begin{array}{l}\text { Atenolol } \\
(224 \mathrm{~nm})\end{array}$ & $\begin{array}{l}\text { Percentage of available } \\
\text { levocetirizine }(\%)\end{array}$ & $\begin{array}{l}\text { Percentage of available } \\
\text { atenolol }(\%)\end{array}$ \\
\hline 0 & 0.00 & 0.00 & 0.00 & 0.00 \\
15 & 0.1293 & 0.0320 & 19.01 & 3.01 \\
30 & 1.4116 & 1.4707 & 382.16 & 53.44 \\
45 & 1.4304 & 1.9113 & 387.52 & 211.12 \\
60 & 1.4382 & 1.9124 & 397.15 & 22146 \\
75 & 1.4401 & 1.9221 & 408.34 & 224.91 \\
90 & 1.4504 & 1.9355 & 409.91 & 230.35 \\
105 & 1.4678 & 1.9381 & 410.78 & 231.25 \\
120 & 1.4853 & 1.9451 & 420.31 & 231.51 \\
\hline
\end{tabular}

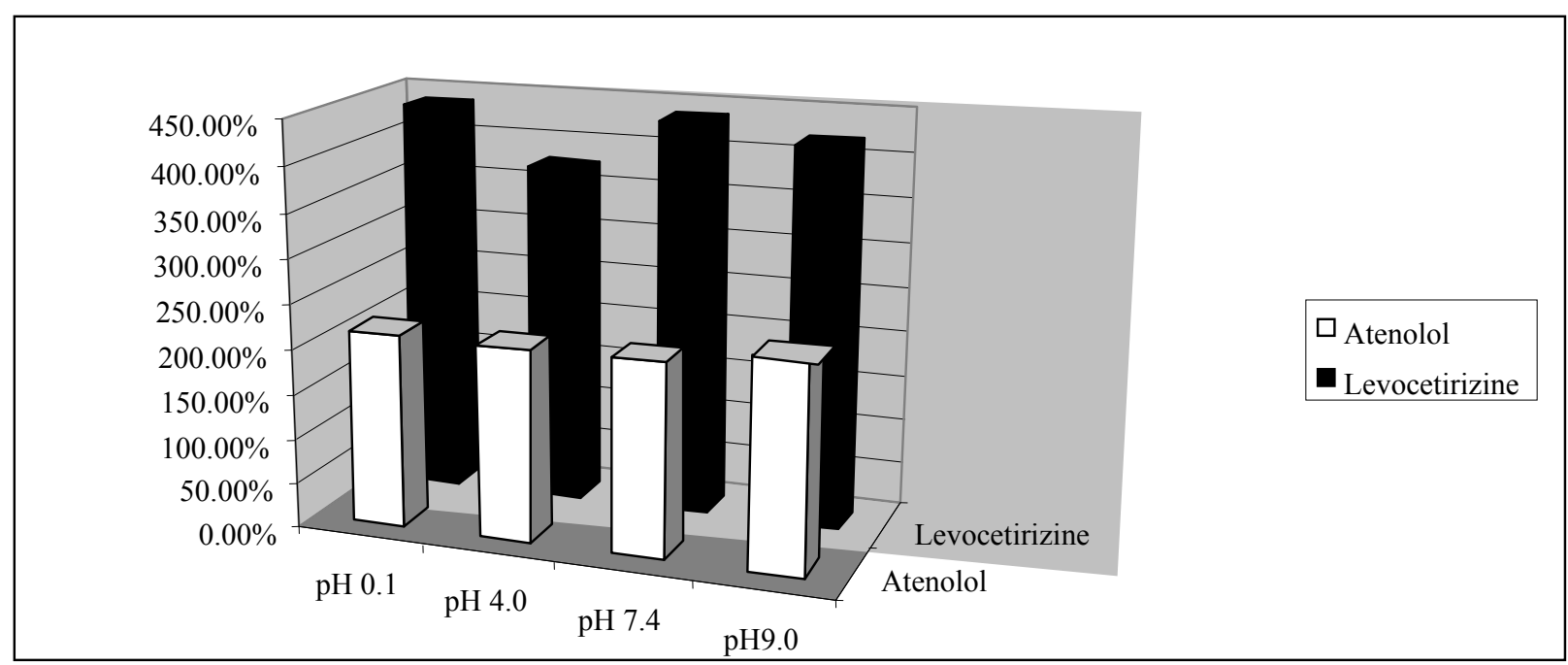

Fig. 3 Maximum percent availability of levocetirizine and atenolol in different $\mathrm{pH}$ after drug interactions.

their absorption. Molar absorptivities were used in calculating the quantities of these drugs in a solution of unknown concentration.

According to Beer's law:

$$
A=\varepsilon b c \text { and } \varepsilon=A / C \cdot b
$$

where, $A=$ absorbance, $\varepsilon=$ molar absorptivity or epsilon, $b=$ path length of the cell $(1 \mathrm{~cm})$, $c=$ concentration of the solution.

If more than two components are present in the solution which was absorbing at the same wavelength, Eq. (1) can be written as;

$$
A=\varepsilon b C_{a}+\varepsilon \quad b C_{b}
$$


where, $C_{a}$ and $C_{b}$ were concentrations of the two components present in the solution and $\varepsilon$ and $\varepsilon$ were the absorptivities of the two components obtained from the absorbance of the standard solution. Similarly, Eq. (2) could be derived for the absorbance taken at another wavelength.

Levocetirizine absorbs maximum at $231 \mathrm{~nm}$ and atenolol at $224 \mathrm{~nm}$, respectively. Let $C_{a}$ be the concentration of levocetirizine and $C_{b}$ is of atenolol. Now Eq. (2) can be written as:

$$
\begin{gathered}
A_{231}=a_{1} b C_{a}+b_{1} b C_{b} \\
A_{224}=a_{2} b C_{a}+b_{2} b C_{b}
\end{gathered}
$$

where, $b$ is $1, a_{1}$ and $a_{2}$ were absorptivities of levocetirizine at $231 \mathrm{~nm}$ and $224 \mathrm{~nm}$, and $b_{1}$ and $b_{2}$ were of atenolol at $231 \mathrm{~nm}$ and $224 \mathrm{~nm}$. By multiplying Eq. (3) with $a_{2}$ and Eq. (4) with $a_{1}$, we get:

$$
\begin{aligned}
& C_{b}=\frac{A_{231} a_{2}-A_{224} a_{1}}{a_{2} b_{1}-a_{1} b_{2}} \\
& C_{a}=\frac{A_{231} b_{2}-A_{224} b_{1}}{a_{2} b_{1}-a_{1} b_{2}}
\end{aligned}
$$

The above Eqs. (5) and (6) were used to calculate the availabilities (\%) of levocetirizine and other drug (atenolol) in the presence of each other [21]. Both the drugs showed more than $200 \%$ availability that is impossible. This may be due to the formation of charge-transfer complex. Therefore, the resultant chelate proved the drug-drug interaction of levocetirizine with atenolol in different $\mathrm{pH}$. Therefore, precaution should be taken by a hypertensive patient while using levocetirizine (an anti-allergic drug) with atenolol. In vivo and large scale studies are highly recommended because as a result of interaction both the drugs can either decrease or even lose their therapeutic effects.

\section{Conclusions}

On the basis of these studies, it is concluded that levocetirizine is a form of charge-complex with atenolol; therefore the co-administration of these drugs should be avoided.

\section{Conflict of Interest}

There is no conflict of interest.

\section{Acknowledgments}

Shafaque Mehboob and Moona Mehboob Khan had conducted all practicals. Dr. Muhammad Azhar Mughal and Prof. Dr. Khalid Aftab involved in writing and calculations. The whole experiment was designed and supervised by Najma Sultana and Syed Arayne. The proposal was approved by BSR from Karachi University of Pakistan.

\section{References}

[1] Block, J., and Beale, J. M. 2003. Wilson \& Gisvold's Textbook of Organic Medical and Pharmaceutical Chemistry. 11th ed. Baltimore: Lippincot Wiliams \& Wilkins.

[2] Ciprandi, G., Cirillo, I., Vizzaccaro, A., Civardi, E., Barberi, S., Allen, M., et al. 2005. "Desloratadine and Levocetirizine Improve Nasal Symptoms, Airflow, and Allergic Inflammation in Patients with Perennial Allergic Rhinitis: A Pilot Study." International Immunopharmacology 5: (13-14): 1800-8.

[3] Cranswick, N., Turzikova, J., Fuchs, M., and Hulhoven, R. 2005. "Levocetirizine in 1-2 Year Old Children: Pharmacokinetic Pharmacodynamic Profile." Int. J. Clin. Pharmacol. Ther. 43 (4): 172-7.

[4] Hulhoven, R., Rosillon, D., Letiexhe, M., Meeus, M. A., Daoust, A., and Stockis, A. 2007. "Levocetirizine Does Not Prolong the QT/QTc Interval in Healthy Subjects." Acta Neurol. Belg. 107 (4): 97-102.

[5] Verster, J. C., Volkerts, E. R., Oosterwijck, A. W., Aarab, M., and Bijtjes, S. I., De Weert, A. M., et al. 2003. "Acute and Sub-chronic Effects of Levocetirizine and Diphenhydramine on Memory Functioning, Psychomotor Performance and Mood." J. Allergy Clin. Immunol. 111 (3): 623-7.

[6] Purohit, A., Melac, M., Pauli, G., and Frossard, N. 2003. "Twenty-Four-Hour Activity and Consistency of Activity of Levocetirizine and Desloratadine in the Skin.” British Journal of Clinical Pharmacology 56 (4): 388-94.

[7] Ulrich, W., Eric, B., Roger, A., and Marie, C. P. 2005. "Levocetirizine in Children: Evidenced Efficacy and Safety in a 6 Week Randomized Seasonal Allergic Rhinitis Trial." Pediatric Allergy and Immunology 16 (3): 267-75. 
[8] Van Eeckhaut, A., and Michotte, Y. 2006. "Chiral Separation of Levocetirizine by Capillary Electrophoresis." Electrophoresis 27 (12): 2376-85.

[9] Dhakam, Z., McEniery, C. M., Cockcroft, J. R., Brown, M. J., and Wilkinson, I. B. 2006. "Atenolol and Eprosartan: Differential Effects on Central Blood Pressure and Aortic Pulse Wave Velocity." Am. J. Hypertens. 19: 214-9.

[10] Devalia, J., DeVos, C., Hanotte, F., and Baltes, E. 2001. "A randomized, Double-Blind, Crossover Comparison among Cetirizine, Levocetirizine, and UCB 28557 on Histamine-Induced Cutaneous Responses in Healthy Adult Volunteers.” Allergy 556 (1): 50-70.

[11] Bachert, C., Bousquet, J., Canoniicca, G., Durham, S. R., Klimek, L., Mullol, J., et al. 2003. "Levocetirizine Improves Quality of Life and Reduces Costs in Long-Term Management of Persistent Allergic Rhinitis.” Journal of Allergy and Clinical Immunology 114 (4): 838-44.

[12] Whomsley, R., Mathy, F. X., Jacques, P., and Canning, M. 2007. "Stereo Selective Renal Tubular Secretion of Levocetirizine and Dextrocetirizine, Two Enantiomers of the HH1-Anti-histamine Cetirizine." Fundamental and Clinical Pharmacology 22 (1): 19-23.

[13] Thiessen, B. Q., Wallace, S. M., Blackburn, J. L., and Wilson, T. W. 1990. "Increased Prescribing of Antidepressant, Subsequent to $\beta$-Blocker Therapy." Arch. Intern. Med. 150: 2286-90.

[14] Abdinee, H., Sultana, M. A., Hefnawy, M. M., and Bilal, F. 2005. "Spectroflurometric Determination of Some $\beta$-Blockers in Tablets and Human Plasma Using 9, 10-dimethoxyanthracene-2-sodium Sulfonate." Pharmazie 60 (4): 265-8.
[15] Sultana, N., Arayne, M. S., Iftikhar, B., and Nawaz, M. A. 2008. "New RPP-HPLC Method for Monitoring of Atenolol: Application to Atenolol Metal Interaction Studies." Journal of Chemical Society of Pakistan 30 (1): 113-8.

[16] Abdul Hamid, M. E. 2000. "Comparative LC-MS and HPLC Analysis of Selected Anti-epileptics and Beta-blocking Drug." Farmaco 55 (2): 136-45.

[17] Sultana, N., Arayne, M. S., and Iftikhar, B. 2008. "Simultaneous Determination of Atenolol, Rosuvastatin, Spironolactone, Glibenclamide and Naproxen Sodium in Pharmaceutical Formulations and Human Plasma by RP-HPLC." Chinese Journal of Chemistry 55 (5): 1022-9.

[18] Wing, L. M., Chalmers, J. P., West, M. J., Bune, A. J., Russell, A. E., Elliott, J. M., et al. 1987. "Treatment of Hypertension with Enalapril and Hydrochlorothiazide or Enalapril and Atenolol: Contrast in Hypotensive Interactions." J. Hypertens Suppl. 5 (5): S603-6.

[19] Bolt, G. R., and Saxena, P. R. 1984. "Interaction of Atenolol with the Systemic and Regional Hemodynamic Effects of Hydralazine the Conscious Renal Hypertensive Rabbits." Pharmacol. Exp. Ther. 230 (1): 205-1356.

[20] Arayne, M. S., Sultana, N., Hashim, M. Z., and Haroon, U. 2010. "In Vitro Studies of Interaction between Metformin and NSAIDs (Non Steroidal Anti-inflammatory Drugs) Using Spectrophotometry and RP-High Performance Liquid Chromatography.” J. Chil. Chem. Soc. 55 (2): 206-11.

[21] Arayne, M. S., Sultana, N., and Nawaz, M. 2014. "Investigation of Levocetirizine with HMG-CoA Reductase Inhibitors." Mod. Chem. Appl. 2 (3):1000134. 